Research Article

\title{
Modified PWM Direct Instantaneous Torque Control System for SRM
}

\author{
Yong Cheng \\ College of Electrical and Control Engineering, Xi'an University of Science and Technology, Xi'an 710054, China \\ Correspondence should be addressed to Yong Cheng; chengbati@gmail.com
}

Received 14 June 2021; Revised 14 August 2021; Accepted 2 September 2021; Published 1 October 2021

Academic Editor: Xiaodong Sun

Copyright ( 12021 Yong Cheng. This is an open access article distributed under the Creative Commons Attribution License, which permits unrestricted use, distribution, and reproduction in any medium, provided the original work is properly cited.

\begin{abstract}
Torque ripple is a defect of switched reluctant motors. DITC (direct instantaneous torque control) is harnessed to solve the problem as a traditional method, which is superior to TSF (torque sharing function). In this paper, a new controller is proposed with modified hysteresis and PWM in DITC. With the modified algorithm, the torque error will be reduced with PWM in DITC. The proposed algorithm is effective to improve sample and 0 status in a period. The modified algorithm is based on application of zero in the asymmetric half bridge, which is implemented as the buffer zone. In case of big torque error, hysteresis will mitigate error under the characteristic of fast responding. In case of small errors, the modified PWM will solve torque error in the equivalent strategy, which has adopted the essence of the impulse equivalent method. The modified controller is designed to reduce responding time and minimize the torque ripple under the proposed algorithm, which has been designed to harness different functions in different torque errors. Based on final simulation and experimental results, responding speed and reduction of output torque ripple are enhanced effectively.
\end{abstract}

\section{Introduction}

Switched reluctant motors [1] (SRMs) have special features such as high tolerance, robustness, low cost with no permanent magnet, and high efficiency without winding in simple and double salient. The torque is stimulated by tendency of rotor poles to align with excited stator pole. SRM is operated by aligned and unaligned rotor to stator position with different torque at different angular position. There are many researching hotspots in SRMs [2-7]. However, in terms of SRM special construction with double salient poles and its nonlinear magnetic characteristics, torque ripple and other problems are more severe than those in other traditional motors. The torque ripple is an accepted bottleneck of widespread application of SRMs. Torque ripple is reduced by modifying geometric structure of salient structure or control algorithm, which is more flexible to control torque ripple than structure optimization. With new algorithm, exciting intensity is controlled with different strategy at different angles, which is according to nonlinear relation between rotor position, stator current, and torque.
In [8], a new type of SRM of flat double stator segmented cup rotor is designed, where components of the radial force are generated when the inner stator and outer stator are opposite. The inner stator and outer stator can cancel each other, while the tangential force component can be added in the same direction, which could reduce torque ripple. In [9], the scholars research angle characteristic of the static moment of SRM. According to the characteristic of TSF (torque sharing function), the conditions of TSF that should be satisfied are analyzed. It is pointed out that the TSF satisfying the condition constitutes a family of functions, which is not unique. As long as the above conditions are satisfied, the zero torque ripple of motor can be achieved in the sense of static torque. At different stages of commutation, the scholars divide the absolute value of flux change rate into different parts in [10]. The torque ripple is solved by using PI controller to compensate for torque and error, respectively. According to the direct torque control of traditional AC motor, the work in [11] put forward the direct torque flux control of three-phase SRM, in which the torque control is employed by application of the magnetic change rate. The 
real-time torque is acquired by checking the torque-currentangle table and interpolation.

At present, a more effective method is adopted in instantaneous torque as controlling object and adjusting the conduction of the power device according to the deviation of the torque. Traditional TSF control scheme based on Lyapunov function is proposed in [10]. After that, improved TSF [11] is implemented in SRM. A new type of active boost power converter with real-time control in winding demagnetization voltage is employed in [12], in which structure is simple. That can achieve high efficiency and low torque ripple operation of SRM under the low speed. The voltage vector pulse width modulation of DITC is introduced in combination with the pulse width modulation technique in [13]. The voltage control vector is employed by calculating torque error and hysteresis, which reduces the further torque ripple under DITC. The control method of inside and outside double hysteresis loop is employed. When two phase windings work together, the sum of the torques generated by the two phases is equal to the instantaneous torque. Torque ripple suppression is employed by adjusting hysteresis threshold [14]. In [15], improved C-dump converter is introduced to higher performance in SRM. In [16], the authors propose direct instantaneous thrust control optimization of a linear switched reluctance actuator, which is combined with PWM.

On the basis of native power, torque character can be promoted by exciting magnetic method, which is relevant to voltage in DITC scheme. Mitigating torque ripple method is different from other motors based on accurate model and easy data acquisition. Hence, the paper presents a new torque ripple reducing method, which is different from traditional SRM torque controlling methods. In terms of the analysis of torque characteristics of SRM, modified PWM-direct instantaneous torque control (MP-DITC) algorithm is introduced with asymmetric half bridge power converter. In the method, the hysteresis strategy and specialized PWM strategy are combined flexibly, and the two algorithms complement each other. According to individual characteristic of single-phase and commutative conduction regions, the proposed strategy is carried out purposefully. The hysteresis strategy under large error and MP-DITC under small error are harnessed.

The main contributions can be generalized as follows:

(1) Almost proposed DITC or full-circle PWM is limited by its characteristics in SRM system, which makes it hard to employ comprehensive consideration in any scheme. In the paper, an improved algorithm combining the two methods is applied, where buffer zone is employed for the first time, which is combined with integration of two strategies.

(2) After detailed discussion and analysis, MP-DITC method is proposed under full combination of the characteristics of circuit and algorithm. MP-DITC method will be based on asymmetric half bridge, which has three states. Meanwhile, state of zero is essential in proposed algorithm, which is analyzed in detail. In short, PWM and hysteresis are meticulously arranged under principle of mitigating torque ripple by zero state, when torque error is limited within error band.

(3) In the strategy, positive (or negative) modulation is performed according to real-time torque deviation, where there are positive or negative carriers in each cycle. Meanwhile, the interrupt of proposed scheme will give full consideration to error variation and dynamic characteristics, which will be combined with different phase characteristic during commutation phase. In MP-DITC, the voltage characteristics of the asymmetric half-bridge drive circuit are evaluated.

In MP-DITC, a new buffering scheme is proposed to mitigate torque error, which is based on asymmetric half bridge. Both theoretical analysis and experimental results reflect that the strategy is an effective method to relieve torque ripple.

The paper is arranged as follows: Section 2 is the main part discussing torque character and comparing with different classical torque control schemes for further analysis of the proposed algorithm. Section 3 is arranged to analyze kernel nonlinear attribute and driver of asymmetric half bridge, which will lead to serious nonlinear characteristics of torque. Section 4 is scheduled to introduce MP-DITC, which has close tie between hysteresis, PWM, and driver. In this part, the proposed algorithm is evaluated in detail. The operating principle of scheme is introduced emphatically. Section 5 shows the simulation result with MATLAB under the distinct operation mode, which will support the principle of strategy. Section 6 verifies the proposed algorithm with experiment. Section 7 concludes the study.

\section{Theoretical Background}

It can be seen from the existing literature that torque ripple will lead to acknowledged weakness of SRM. Therefore, the majority of scientific research in this field is hot for most researchers. In Reference [17], a novel average torque control of SRM is introduced, which is based on flux-current locus control. In practice, it may be difficult to acquire accurate flux. In Reference [18], a torque-flux linkage recurrent neural network adaptive inversion control is employed in torque control, which is benefit from the accurate approximation nonlinear model of neural network. Nevertheless, this may make the model sophisticated and produce heavy burden of the processor. In Reference [19], phase-current waveform for switched reluctance motors is analyzed, which is applied to mitigate input-current ripple and torque ripple in low-power propulsion below magnetic saturation. This procedure may make system complicated. In Reference [20], the paper is analyzing of switch angle based on analytical modelling, which is crucial to torque characteristic. In 
Reference [21], the paper introduced two modified DITC, where the commutation instants are dynamically adjusted according to the varied operation conditions. For each phase, the turn-ON and turn-OFF angles are modified for high performance. Hysteresis is key to higher performance, which is set under constant experimentation and experience. In Reference [22], for the sake of the hysteresis controller in traditional DITC, the PWM is introduced to modulate the torque deviation. However, there is no comprehensive consideration of the characteristics of the two methods, and integrate them together. In Reference [23], the paper proposes that the torque hysteresis remained in the system is similar to direct torque control (DTC) and direct instantaneous torque control (DITC). The candidate voltage vectors (VVs) are selected from the torque hysteresis and the cost function is designed for the flux linkage minimization to select the best VV from candidate VVs. Robert B Inderka is devoted to DITC, who has achieved a lot of results [24-26] in this field. He proposed DITC with hysteresis, which is the classic method in closed-loop control system. In [27], DITC is applied in wide operation range. In [28], a 4-level converter is applied in SRM with DITC. In [29], a simple strategy for parameters identification is employed in DITC. In [30], the DITC is applied in electric vehicles. All these DITC strategies above are based on hysteresis or modified, which is simple and empirical. Moreover, hysteresis is easy to cause system overshoot or exceed the range of frequency response, although it is easy to achieve. TSF is another effective function in the torque control strategy, which is based on the sharing function to reduce torque ripple. In terms of TSF, the desired torque of each phase is calculated by the sharing function, which will follow the target torque by reversely computing current. However, TSF has two steps at least in torque loop, which are the calculation of desired torque and applied current. It is more complicated than DITC; what is more, the sharing function is another significant part in TSF. The function in TSF is distributing torque as reasonably as possible, but it may be easier to make TSF more complicated than DITC.

\section{Basic Characteristic of SRMs}

SRM is a typical electrical machine with converters, which converts electrical power to mechanical power. With salient pole structure of SRM, this structure produces a high output cluster of torque with different current and position. At alignment between rotor and stator, reluctance was minimized and excited induction was maximized.

$$
\psi_{k}=L_{k}\left(\theta, i_{k}\right) i_{k}(\theta) .
$$

In equation (1), $k$ is the serial number of stator winding, and $\psi_{k}$ is flux linkage of phase winding, which is function of $i_{k}$ and $\theta$. If the mutual induction is neglected, flux linkage $\psi_{k}$ is the product of induction $L_{k}$ and current $i_{k}$.

The following equation gives a description of voltage characteristic function in one phase:

$$
\begin{aligned}
U_{D C} & =R_{k} i_{k}+\frac{\partial \psi_{k}}{\partial i_{k}} \frac{\mathrm{d} i_{k}}{\mathrm{~d} t}+\frac{\partial \psi_{k}}{\partial \theta} \frac{\mathrm{d} \theta}{\mathrm{d} t}, \\
& =R_{k} i_{k}+\left(L_{k}+i_{k} \frac{\partial L_{k}}{\partial i_{k}}\right) \frac{\mathrm{d} i_{k}}{\mathrm{~d} t}+i_{k} \frac{\partial L_{k}}{\partial \theta} \frac{\mathrm{d} \theta}{\mathrm{d} t},
\end{aligned}
$$

where $U_{\mathrm{DC}}$ is the DC bus voltage, $R_{k}$ is the equivalent reluctance of $k$-th stator winding, and $i_{k}$ is the current of stator winding.

In Figure 1, if rotor is rotating counterclockwise, $a-a^{\prime}$ will be aligned to $A-A^{\prime}$ and produce positive torque when switches $T_{k U}$ and $T_{k D}$ are turned on. In the asymmetric bridge inverter, every phase of stator is conducting by turn, producing exciting magnet in rotor rotating. In asymmetric inverter, each phase has two switches and two freewheeling diodes. Under single-phase conducting states, there are three states in asymmetric inverter, which are $+1(+U),-1(-U)$, and $0(0)$ in Figure 2.

Consider the case of the $k$-th phase winding conducting, if $T_{k U}$ and $T_{k D}$ are turning on together, winding will exert positive voltage to stimulate magnetic power from DC source, which can produce current and magnetic flux. Electromagnetic torque will increase rapidly, and state at that stage is defined as +1 , as shown in Figure 2(a).

If $T_{k U}$ was turning on and $T_{k D}$ was turning off, winding current would be freewheeling under zero voltage, which is defined as 0 . Electromagnetic torque will decrease slowly as shown in Figure 2(b). If $T_{k U}$ and $T_{k D}$ were turning off together, winding would reversely discharge in the discharge state. Electromagnetic torque will decrease rapidly, and current state is defined as -1 , which is shown in Figure 2(c).

\section{Direct Instantaneous Torque Controlling Strategy}

4.1. Theory of the Proposed Torque Controller. According to basic nonlinear equation in SRM driving [1], each phase stator current can be simplified in (3), where phase current can exert magnetic torque in different position.

It can be seen that the current relation can be deduced as follows: 


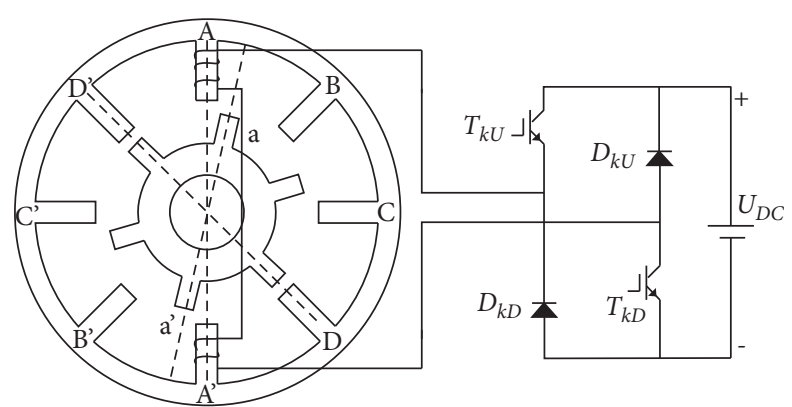

FIGURE 1: Basic structure of SRM and driving topology.

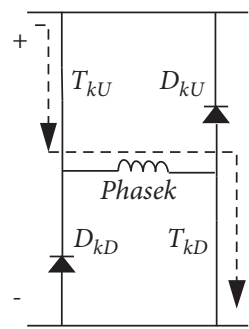

(a)

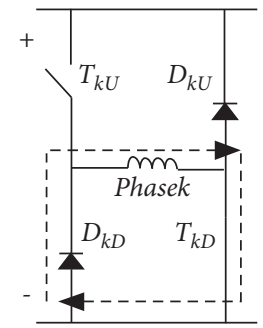

(b)

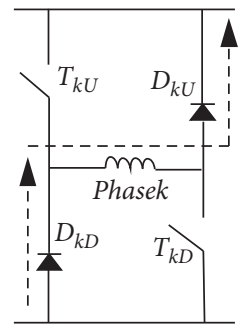

(c)

FIgURE 2: Voltage state in the asymmetric half bridge drive. (a) $S k=1$. (b) $S k=0$. (c) $S k=-1$.

$$
\begin{aligned}
& i_{k}=\frac{U_{k}}{\left(\partial L_{k} / \partial \theta\right) \omega}\left[1-\exp \left(\frac{-\left(\partial L_{k} / \partial \theta\right) \omega}{L_{k}} t\right)\right]+i_{0}\left(t_{0}\right) \exp \left(\frac{-\left(\partial L_{k} / \partial \theta\right) \omega}{L_{k}} t\right), \\
& T=\frac{1}{2} i_{k}^{2} \cdot \frac{\partial L_{k}\left(i_{k}, \theta\right)}{\partial \theta} .
\end{aligned}
$$

According to Taylor series, there is

$$
\begin{gathered}
\exp \left(\frac{\left(\partial L_{k} / \partial \theta\right) \omega}{L_{k}} t\right) \approx 1-\frac{\left(\partial L_{k} / \partial \theta\right) \omega}{L_{k}} t, \\
i_{k}=\frac{U_{k}}{L_{k}} t+i_{0}\left(t_{0}\right)\left(1-\frac{\left(\partial L_{k} / \partial \theta\right) \omega}{L_{k}} t\right), \\
T_{k}=\frac{1}{2}\left(\frac{U_{k}}{L_{k}} t+i_{0}\left(t_{0}\right)\left(1-\frac{\left(\partial L_{k} / \partial \theta\right) \omega}{L_{k}} t\right)\right)^{2} \frac{\partial L_{k}}{\partial \theta} .
\end{gathered}
$$

Equation (7) reveals inherent relation between current $i_{k}$, induction $L_{k}$, and different rotor angle. Moreover, torque relation (3) can be explained as torque is typical nonlinear variable to current and induction. The induction is function to current $i_{k}$ and position angle $\theta$ and has periodic exchanging from increase to decrease at different position angle and current. In Figure 3, three phases of SRM are regarded as example, the polar angle of which is $90^{\circ}$. According to Figure 3, torque in equation (3) is positive at $\partial L_{k} / \partial \theta>0$ and negative at $\partial L_{k} / \partial \theta<0$. It is very clear that torque is positive and continuous at $\partial L_{k} / \partial \theta>0$. In fact, it is difficult to obtain accurate information of SRM inductance with position angle because of the constraints of noise detection and low self-inductance and mutual inductance. In particular, the adopted method should follow the principle of reducing the impact on the system. When releasing energy, the output torque and winding energy should be gradually mitigated from slow to fast. If “ -1 " is added prematurely, it may cause torque ripple and system oscillation.

4.2. Analysis of Hysteresis Control in DITC. The characteristics of voltage can be effectively employed to control excitation in DITC. The voltage control method is applied in the torque control of SRM, which is implemented in the closed-loop control of the torque. However, the classic DITC method often selects the voltage control based on the hysteresis strategy, which often leads to larger torque overshoot. This is obviously a difficulty that cannot be adopted in the implementation of traditional DITC. The duty cycle of the equivalent voltage is calculated in the existing PWM algorithm, according to torque value in each sampling period and different phases. Although this method can implement the control of MP-DITC, the fixed-precise duty cycle can suppress torque ripple, but it may employ too many resources for MCU (DSP, FPGA).

In the classic electrical control algorithm, PWM technology successfully combines the principle of impulse equivalent control with variable control. Moreover, voltages with different 


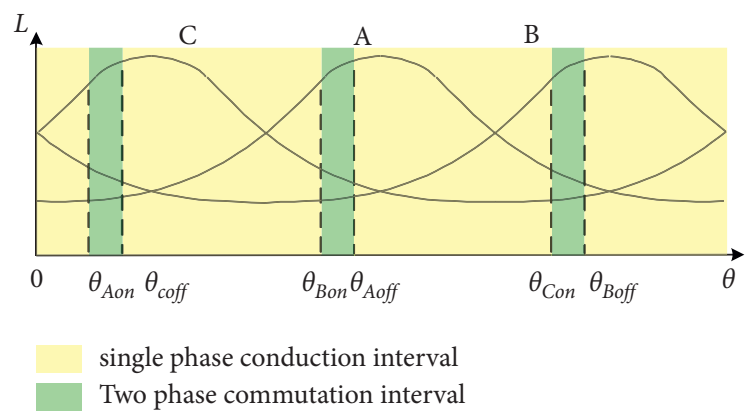

Figure 3: Relation between induction and position angle.

duty cycles are applied in a fixed period to effectively control the average voltage value in each period. In the traditional DITC method, the hysteresis strategy is employed to control the output voltage under asymmetric half bridge driver, which can effectively control the output torque at three different levels. This kernel of MP-DITC is designed to make full use of voltage, which combines the PWM and DITC. According to the characteristics of the output level of the asymmetric half bridge and the control characteristics of the DITC control, a method of quantifying duty PWM, which is adopted to adjust the torque error, is judged by operation condition. This scheme considers full attributes of driver, which are divided into fast and meticulous control areas. In the fast adjustment zone, the algorithm will adopt +1 or -1 , in which the system needs to respond quickly to reduce error. If the torque error is within small error limit, the light adjustment method is employed by PWM. This method can optimize efficiency of MCU and at the same time can maintain the torque control accuracy.

According to the previous research, traditional direct instantaneous torque controlling (DITC) is based on hysteresis. Theory of DITC is regulated voltage of stator winding, which can control excitation intensity and magnetic power $[14,15]$. However, for the sake of superior regulation performance, torque loop should be satisfied with fast, stable, and accurate attributes. In closed-loop structure, acquiring accurate instantaneous torque is difficult and crucial. Generally speaking, there are two ways of measuring torque, which are look-up torque table and real-time measuring [16]. The former is based on offline table, which is looked up with detected current and position. Nevertheless, accurate table is hard to acquire. Another feasible acquirement depends on torque sensor, which is accurate and costly. In this paper, the research focus is on torque control strategy, so the latter method is adopted.

Hysteresis strategy of DITC is simple and effective. However, boundary of torque error is critical in DITC, which is important and experienced. If the set of thresholds is bigger, torque ripple will be obvious, which can lead to overshooting and reducing performance of torque output. On the contrary, if the set is smaller, the error of torque will be limited within band of error boundary theoretically. Nevertheless, small error boundary in hysteresis DITC strategy will result in out-of-frequency response to IGBT when the algorithm is in excessive pursuit of higher characteristics by reducing torque error limit.
4.3. MP-DITC Strategy. The MP-DITC strategy is proposed in this paper. This method takes into account both advantages of hysteresis strategy and PWM equivalent strategy. From the perspective of rapid response, hysteresis strategy is a nice choice in large error range. When the torque error $\left(T_{\text {err }}\right)$ converges in the error limit, the closed-loop torque employs PWM equivalence principle to generate meticulous voltage under PWM cycle. Without doubt, MP-DITC should be executed by phase angle. Beyond question, different phase means different needs and strategy.

The schematic diagram of MP-DITC is shown in Figure 4 . The output torque is measured directly by the torque sensor, and the speed error is controlled by PID, which is reference torque to inner torque loop. Torque error $T_{\text {err }}$ is acquired by comparing reference torque with instantaneous torque. According to superior performance, upper and lower limit thresholds of torque error are $T_{U_{+}}$and $T_{U_{-}}$, which are numbers opposite $\left(T_{U_{+}}=-T_{U_{-}}\right)$to each other.

The threshold of hysteresis strategy is core point in hysteresis of traditional DITC. The principle of MP-DITC will be introduced from perspective of conduction, phase angle, and natural sampling of PWM.

4.3.1. Conduction of Phase. In the paper, single-phase operation mode is applied, which means two modes in every phase conduction. In the conduction mode of single phase, there are almost two stages of this mode, which are single phase and overlapping conduction regions. In particular, in commutation state, the phase to shut off is defined as outgoing phase, and independent operation of phase is incoming phase. For outgoing phase, the main task is to assist in torque output, which is mainly responsible for torque reduction. For incoming, it will operate independently after commutation, which should increase the torque output as much as possible. Furthermore, in single-phase conduction mode, conducting phase will control torque error within limit, which is operated by bipolar PWM.

4.3.2. $M P W M$. Considering the torque ripple characteristics of SRM, there are three significant differences from the traditional PWM principle:

The first difference is carrier. Modified PWM has two polar carrier signals in each PWM cycle, though only one kind of carrier participates. 


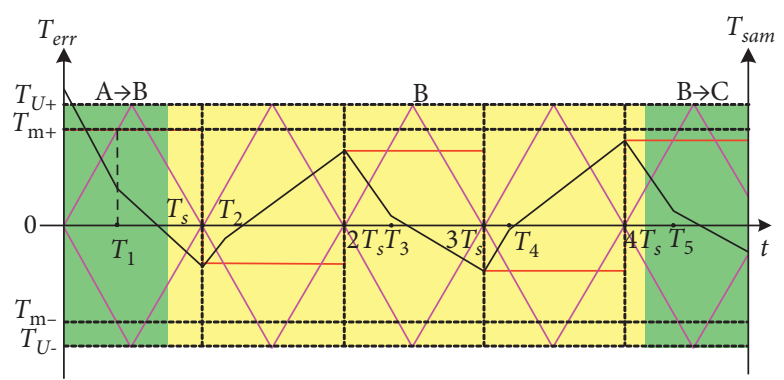

single phase conduction interval

Two phase commutation interval

(a)

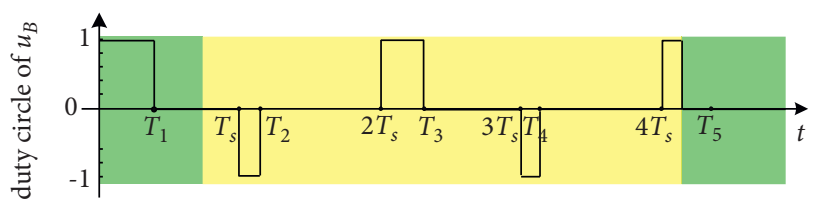

single phase conduction interval

Two phase commutation interval

(c)

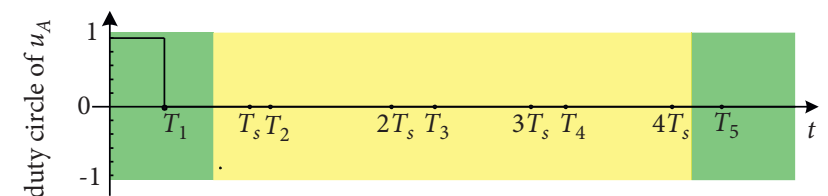

single phase conduction interval

Two phase commutation interval

(b)

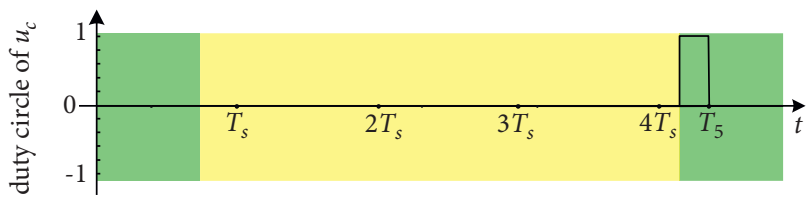

single phase conduction interval

Two phase commutation interval

(d)

Figure 4: Control scheme of the MP-DITC strategy. (a) Torque error and sampling of torque error, (b) duty circle of $u_{A}$, (c) duty circle of $u_{B}$, and (d) duty circle of $u_{C}$.

The second is sampling. MPWM will execute sampling, when error converges between $T_{m+}$ and $T_{m-}$ at every $T_{s}$. In other words, sampling is determined to process by whether the error is out of bounds.

The third is modulation. If $T_{\mathrm{err}} \in\left(T_{m-}, T_{m+}\right)$, PWM will be harnessed with one type of carrier. If $T_{\text {err }}$ is convergent to reverse polarity, the buffer principle will be adopted with zero voltage. Through analysis and comparison, zero voltage is effective in buffer error, which is lightly release of energy for SRM. Considering a circumstance, if $T_{\text {err }} \in\left(0, T_{m+}\right)$, PWM will reduce torque error. With torque error reducing, in which $T_{\text {err }}$ converts the polarity, status of 0 (zero voltage) will be executed to buffer this trend. If the error is overshoot to negative fields, status of 0 (zero voltage) will be harnessed. In terms of speediness of new controller, once the error of torque is reduced within error band $\left(T_{m-} \leq T_{\text {err }} \leq T_{m+}\right)$, the latest sampling will be restarted to exert strategy of PWM.

In commutation period, incoming phase should be modulated with 0 and $+U_{\mathrm{DC}}$ unipolar levels, where sampling of torque error is positive. In the same way, strategy of outgoing can be defined the same as incoming. Nevertheless, in negative field, incoming will be preserved for the coming single-phase operation state. On the contrary, outgoing will undertake reducing output torque, where incoming is 0 in preservation principle. Details of the proposed strategy are given in Table 1.

The modified algorithm should be allowed following the given principles:
(1) Boundary Principle. If torque error is out of upper and lower boundary, hysteresis will be launched to prevent greater torque error. In particular, when torque error is bigger than $T_{m+}$, output torque is not big enough so that proposed strategy will adopt +1 as voltage propulsion. If it is less than $T_{m-},-1$ will be harnessed to reduce output torque as quickly as possible.

(2) Sample Principle. According to responding time, we set different value as sampling and saturated limit, where sampling is harnessed as torque error restrained within effective zone. There are usually two cases. In first case, torque error is out of upper $\left(T_{U_{+}}\right)$ or lower $\left(T_{U_{-}}\right)$limit, and sampling of torque error is $k$ times $T_{U_{-}}$or $T_{U+}$, where $k$ is within 0 to 1 . Once the torque error recovery is within boundary $\left(T_{m_{-}} \leq T_{\mathrm{err}} \leq T_{m+}\right)$, new sampling process restarts at that time. After that, MPWM strategy is launched. If the torque error is out of positive or negative limit, hysteresis will restart to reduce torque ripple.

4.4. Buffering Zone and Zero Crossing. Considering the instantaneous characteristics of torque, there are positive and negative carriers in each cycle. When torque error is between $T_{m+}$ and $T_{m-}$, PWM will be exerted to reduce torque error furthermore. If torque error is between 0 and $T_{m+}$, it is denoted that driving system needs more power and PWM strategy will be executed with positive triangular carrier. Following the natural sampling principle of PWM, if value of sampling is more than positive carrier, PWM is +1 , which 
TABle 1: Scheme of the modified PWM-DITC.

\begin{tabular}{lcc}
\hline $\begin{array}{l}\text { Status of sampling or error } \\
\text { Conduction of torque }\end{array}$ & Single-phase conduction & $\begin{array}{c}\text { Two-phase commutation } \\
\text { Outgoing }\end{array}$ \\
\hline$T_{\mathrm{err}} \geq T_{\mathrm{m}+}$ & $T_{\mathrm{sam}}=T_{\mathrm{m}+}$ & 1 (hysteresis zone) \\
$T_{\mathrm{err}} \leq T_{\mathrm{m}-}$ & $T_{\mathrm{sam}}=T_{\mathrm{m}-}$ & -1 (hysteresis zone) \\
& $T_{\mathrm{m}+} \geq T_{\mathrm{sam}} \geq 0$ & Natural sampling (PWM zone) \\
$T_{\mathrm{m}+}>T_{\mathrm{err}}>T_{\mathrm{m}-}$ & $T_{\mathrm{err}}<0$ & 0 (buffering zone) \\
& $0 \geq T_{\mathrm{sam}} \geq T_{\mathrm{m}-}$ & Natural sampling (PWM zone) \\
& $T_{\mathrm{err}}>0$ & 0 (buffering zone) \\
\hline
\end{tabular}

indicates output torque will increase evidently. In the same way, if sampling is less than positive carrier, PWM is 0 , which means output torque decreases gradually. At this stage, if torque deviation becomes negative, which denotes that output torque is greater, strategy will adopt 0 to buffer this error increasing. If output torque continues to increase so that torque error is less than $T_{m-}$, hysteresis will start to reduce this error with -1 state. Generally, 0 status is applied to soften former output, which is also implemented to modify former PWM status in one PWM cycle.

In Figure 4, the main purpose is to illustrate the characteristics of scheme with MP-DITC. In full consideration of outside the error limit and PWM, details of strategy are illustrated. It should be noted that the figure here is schematic expression, reflecting the trend and characteristics of torque error.

In Figure 4, there are yellow and green zones, which are defined as single-phase conduction and commutation. In Figure 4(a), purple line denotes positive and negative carrier, red means sampling of torque error, and bold black line indicates instantaneous torque error. In Figure 4(a), the vertical axis shows torque error, in which special scale is defined as $T_{U_{+}}\left(T_{U_{-}}\right), T_{m+}\left(T_{m_{-}}\right)$, and $T_{n+}\left(T_{n-}\right) . T_{U_{+}(-)}$is error quantization boundary value, which shows torque error big or small enough. $T_{m+(-)}$ is $k$ times $T_{U_{+}(-)}$, which is critical condition of calling direct +1 or -1 state of driver. $T_{s}$ is a PWM cycle. In Figure 4(a), torque error is bigger than $T_{U_{+}}$. Outputs of phase $\mathrm{A}$ and phase $\mathrm{B}$ are both +1 , in which sampling of torque error is $T_{m+}$ until first $T_{s}$. When torque error is less than $T_{m+}$, natural sampling method of PWM is harnessed, which means output of $\mathrm{A}$ and $\mathrm{B}$ is bigger than positive triangular carrier at +1 state. After $T_{1}$, PWM of $u_{A}$ and $u_{B}$ will be 0 with natural sampling. Of particular note is the fact that boundary between yellow and green areas means phase A is turned off and phase A will be conducted alone. When torque error is reduced as torque increases, until it is crossing zero of vertical axis, $u_{A}$ and $u_{B}$ are 0 to first $T_{s}$. From $T_{s}$ to $2 T_{s}$, PWM is triggered with negative triangular carrier. Phase $\mathrm{A}$ is -1 between $T_{s}$ and $T_{2}$. When torque error is positively crossing zero error at $T_{2}$, buffer strategy is launched as alleviating trend of torque error from $T_{2}$ to $2 T_{s}$. The same process will be repeated in the following time, and the analysis process will not be repeated.

It should be noted that there are two levels of interruption with different priorities. The first level interruption is error out of upper and lower bound. In any process, if torque sampling is out of bound, the algorithm will be executed in highest priority. The second interruption is that commutation condition is triggered, which means angle is continuously changing from single conduction to commutation in cycles. This interruption has middle priority. In Figure 4(a), circle of PWM is $T_{s}$. However, if interruption is triggered in PWM circle, $T_{s}$ is reduced as intervals from $\Delta T_{1}$ to $\Delta T_{7}$. It is also noted that a new circle will launch after out of boundary or end of commutation. After PWM circle is launching, $\Delta T_{2}$ is effective output time with commutation interruption. In single-phase conduction, PWM circle is reset, and $\Delta T_{3}$ is valid output interval before the impending interruption. Subsequently, interruption of out of boundary has occurred within $\Delta T_{4}$. After out of boundary, a new circle will restart again.

Considering characteristics of drive and the hysteresis limit, the application of $\pm U_{\mathrm{DC}}$ to the winding will rapidly charge and discharge, which will inherit the advantages of hysteresis. Therefore, the output voltage per cycle can be performed by employing impulse equivalence principle in the strategy, which can simplify standard PWM algorithm. The advantages of the two methods are combined to achieve efficient torque control.

\section{Units Analysis of Simulation}

In order to verify the feasibility of the MP-DITC strategy described in this paper, a simulation model is established in MATLAB/Simulink, and a three-phase 6/4 SRM is employed. The rated voltage of SRM is $240 \mathrm{~V}$, and rated power is $5 \mathrm{~kW}$. In the simulation of DITC hysteresis control, the turn-on angle is set to $5^{\circ}$ and the turn-off angle is set to $40^{\circ}$. Simulation system is designed in Figure 5, which is constructed with two closed loops. Outer loop is speed loop, which is controlled by PID controller. Inner loop is torque loop. In order to compare the characteristics of the two torque algorithms, DITC and MP-DITC are applied with the same speed loop setting.

The hysteresis limit of the torque controller is $0.8 \mathrm{Nm}$. The load torque is changed from $3 \mathrm{Nm}$ to $10 \mathrm{Nm}$, and the given speed $n$ is $600 \mathrm{rpm}$. In the MP-DITC system, it has same angle settings, speed, and load characteristics. Since the load is changed from $5 \mathrm{Nm}$ to $3 \mathrm{Nm}$, the threshold was chosen as $0.5 \mathrm{Nm}$. The waveform of DITC hysteresis in simulation is shown in Figure 6. The waveform of MP-DITC system is shown in Figure 7.

In Figure 6(a), purple line is PWM signal of phase A, red line denotes torque error, and black and green are positive and negative carriers. In Figure 6(b), yellow line denotes PWM of phase B, blue line is sampling torque error, and 


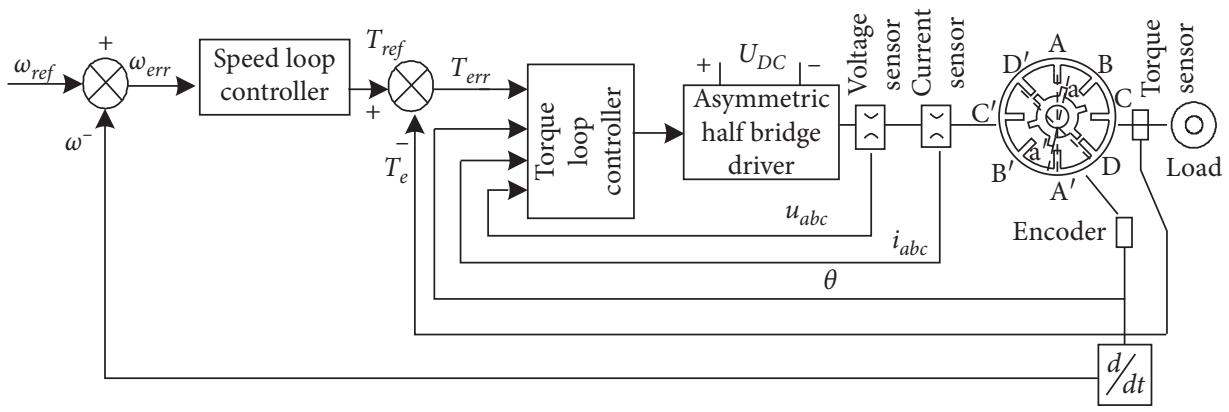

FIGURE 5: Structure of the simulation system.

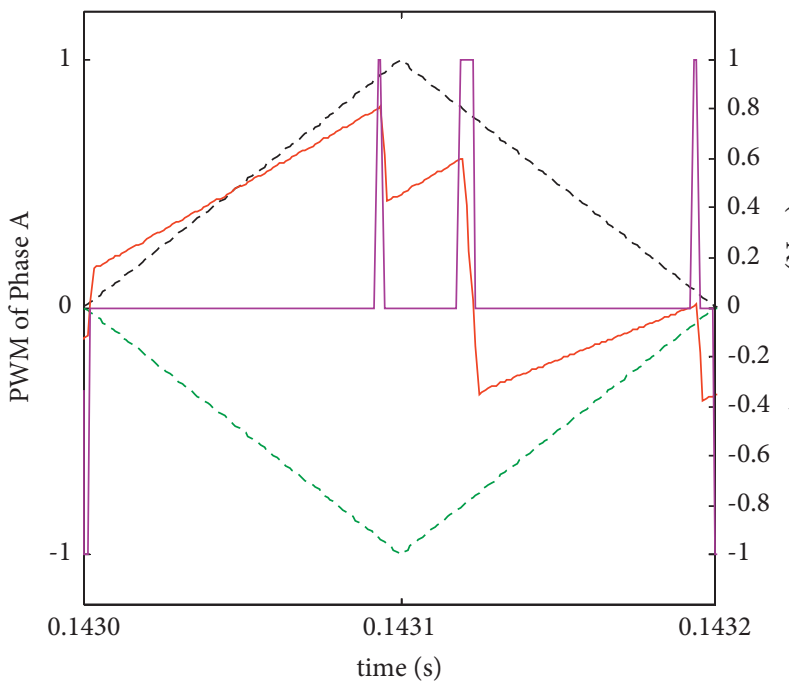

(a)

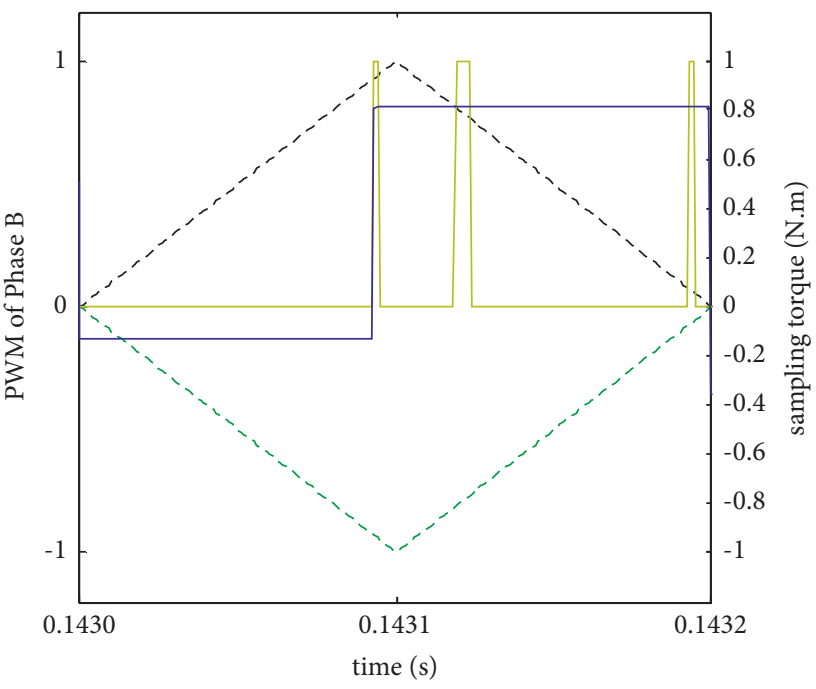

(b)

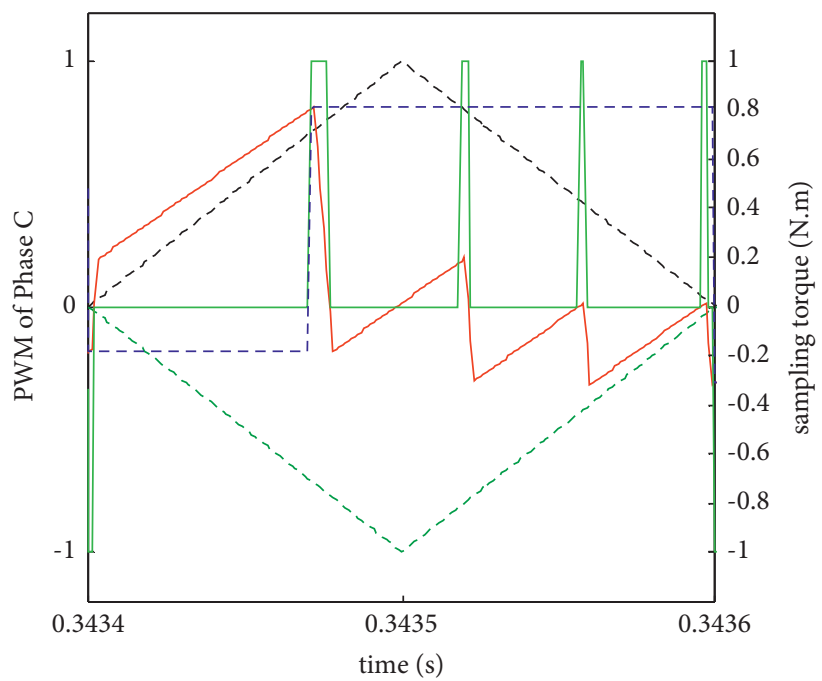

(c)

Figure 6: Operation of MP-DITC with commutation and single-phase conduction. (a) PWM of phase A and instantaneous torque error during commutation conduction. (b) PWM of phase B and sampling of torque error during commutation conduction. (c) PWM of phase B and sampling of torque error during single-phase conduction.

black and green are carriers. Figures 6(a) and 6(b) are commutation status. In commutation process, phase $\mathrm{A}$ is outgoing phase and phase B is incoming. At $0.143 \mathrm{~s}$, value of sampling is $0.24 \mathrm{Nm}$, which is smaller than $0.2 \mathrm{Nm}$. Phase B is preserved to reduce torque with 0 . Nevertheless, task of reducing is executed by phase A with -1 ; and torque error is 


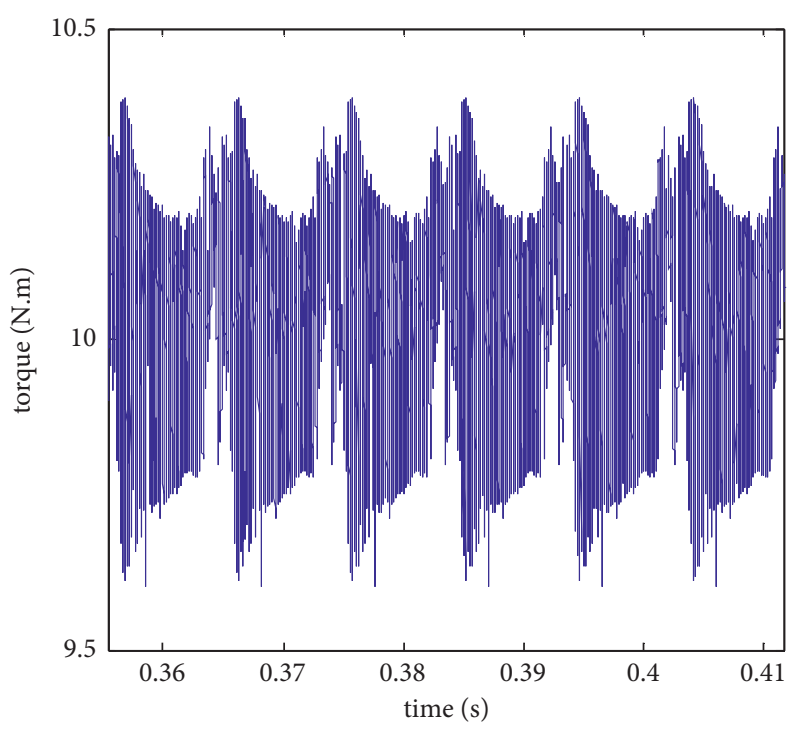

(a)

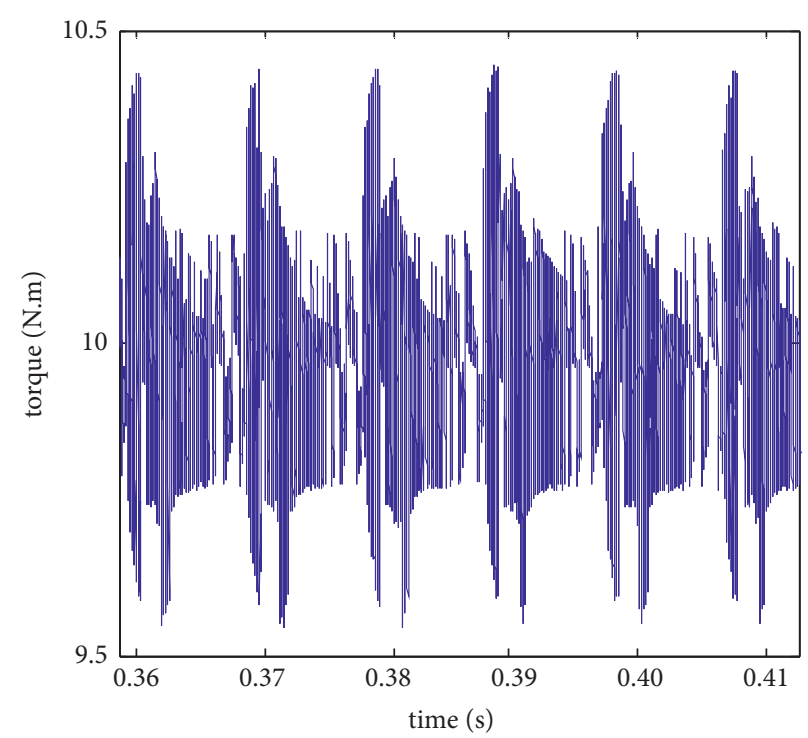

(b)

FIgURE 7: Waveform diagram of the MP-DITC and DITC system. (a) Torque waveform of MP-DITC. (b) Torque waveform amplification diagram during stable operation of HDITC.

rapidly decreasing, which is bigger than $-0.2 \mathrm{Nm}$. In this circumstance, buffer principle is employed, where state of phase $\mathrm{A}$ is 0 to reduce trend of torque error. Condition changed very soon, where torque error is bigger than $0.8 \mathrm{Nm}$. This circumstance is triggering hysteresis to reduce torque error in positive field, where sampling torque error is changed at $0.8 \mathrm{Nm}$. From Figure 6(a), phase A and phase B are both executed +1 to promote torque. With this response, torque error is converged and is less than $0.8 \mathrm{Nm}$, where PWM strategy is employed again. At about $0.14313 \mathrm{~s}$, natural sampling is harnessed to reduce error, in which torque error is reduced and is less than $0 \mathrm{Nm}$. Immediately, buffering principle is employed by 0 of phases A and B. With hysteresis, PWM, and buffering zone, torque error is reduced between limited error bands.

In Figure 6(c), phase $\mathrm{C}$ is single conduction. At $0.3434 \mathrm{~s}$, error and sampling of torque are negative. Output PWM in phase $\mathrm{C}$ is negative status, which lasts about 2 us, and torque error is decreased bigger than $-0.2 \mathrm{Nm}$, where PWM of $\mathrm{C}$ is 0 . The trend of error increase is obviously reduced. Until $0.343475 \mathrm{~s}$, toque error is bigger than $0.8 \mathrm{Nm}$, where hysteresis is employed by +1 of PWM; and torque error is decreased to negative, in which buffering scheme will employ 0 . Until torque error increases and becomes bigger than $0.2 \mathrm{Nm}, \mathrm{PWM}$ is launched at $0.34352 \mathrm{~s}$.

From equation (8), the ripple level of torque is defined. $T_{\max }$ is max output torque, $T_{\min }$ is min torque, and $T_{\mathrm{av}}$ is average torque over a period.

$$
K_{T}=\frac{T_{\max }-T_{\min }}{T_{\mathrm{av}}} \times 100 \% .
$$

In Figure 7, target torque is $10 \mathrm{Nm}$ with $5 \mathrm{Nm}$ load torque. In Figure 7(a), MP-DITC is compared with hysteresis DITC (Figure 7(b)) in steady state. Meanwhile, envelope characteristics of two strategies are different. The advantage of MP-DITC system is flexible use of PWM strategy under small error. So it is clear that output torque is more continuous and uniform than traditional DITC, which is more unexpected than MP-DITC under hysteresis at center of torque. $K_{T}=0.82$ in DITC, while $K_{T}=0.63$ in MPDITC.

\section{Experimental Verification Results}

The traditional DITC hysteresis control system and the HYPWM-DITC system are compared with each other on a $10 \mathrm{~kW}$ three-phase 6/4 SRM platform. The rated parameters of the motor are as follows: $P_{n}=10 \mathrm{~kW}, U_{n}=512 \mathrm{~V}$, and $n_{n}=1500 \mathrm{rpm}$. Torque instantaneous value is measured directly by torque sensor of WDH100B1, and torque sampling signal is square wave, frequency of which is between $5 \mathrm{kHz}$ and $15 \mathrm{kHz}$ equal torque from $-50 \mathrm{Nm}$ to $+50 \mathrm{Nm}$. The magnetic powder brake is FKB-20XN/J, upper computer data are processed with LABVIEW, basic controller TMS320F28335 is float c2000 serial microcontroller in Texas instruments, the incremental encoder is ZKT8030-002J2000BZ2-5E, the position signal is decoded by FPGA EP4CE10E22C8N of Altera and communicates with DSP through SPI protocol, the IGBT as well as its intelligent controller is Infineon IGBT F4-150R12KS4 and 2SC0108T of CONCEPT. The physical diagram of the experimental system is shown in Figure 8, the experimental waveform of HYPWM-DITC system is shown in Figure 9, and the experimental waveform of DITC hysteresis control system is shown in Figure 10.

Comparing Figure 9(a) with Figure 9(b), when the motor runs stably at $800 \mathrm{rpm}$, load is $23 \mathrm{Nm}$, the torque of $\mathrm{MP}$ DITC system is between $23.1 \mathrm{Nm}$ and $24.6 \mathrm{Nm}$, and the torque ripple is $1.5 \mathrm{Nm}$. When the load is reduced from $23 \mathrm{Nm}$ to $19 \mathrm{Nm}$, the adjusting time is $0.4 \mathrm{~s}$. When the load is 


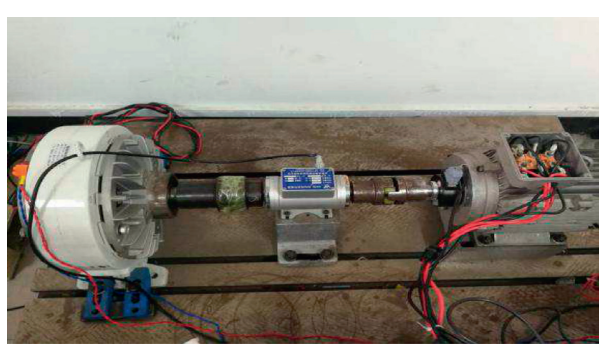

(a)

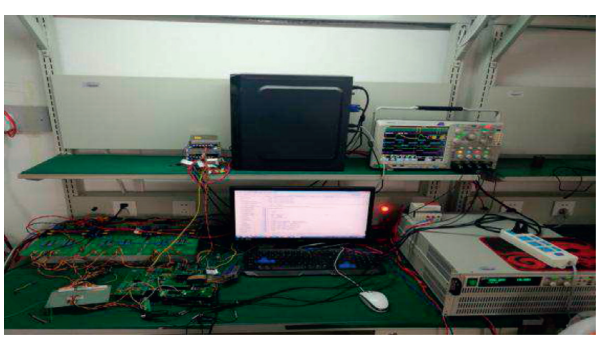

(b)

Figure 8: Physical diagram of the experimental system. (a) Experimental platform I. (b) Experimental platform II.

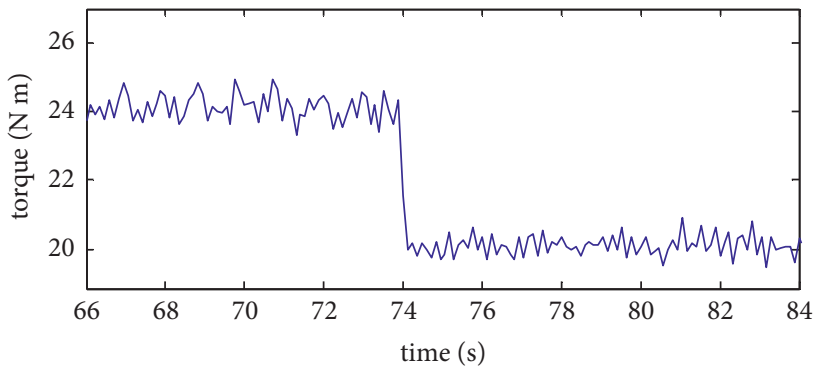

(a)

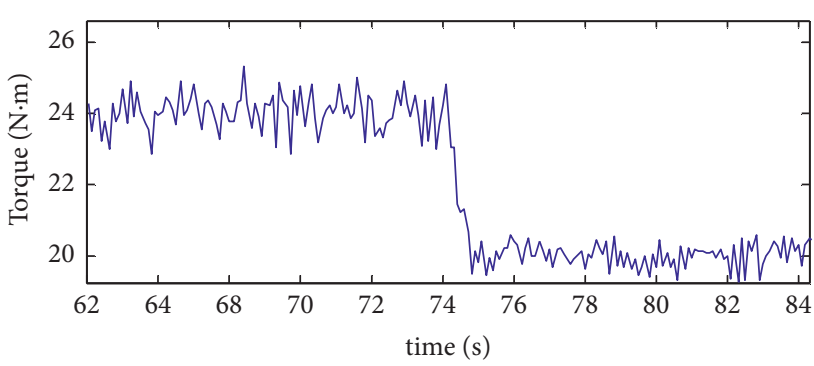

(b)

Figure 9: Experimental waveform diagram of the DITC and MP-DITC control system. (a) Torque waveform diagram in MP-DITC. (b) Torque waveform diagram in DITC.

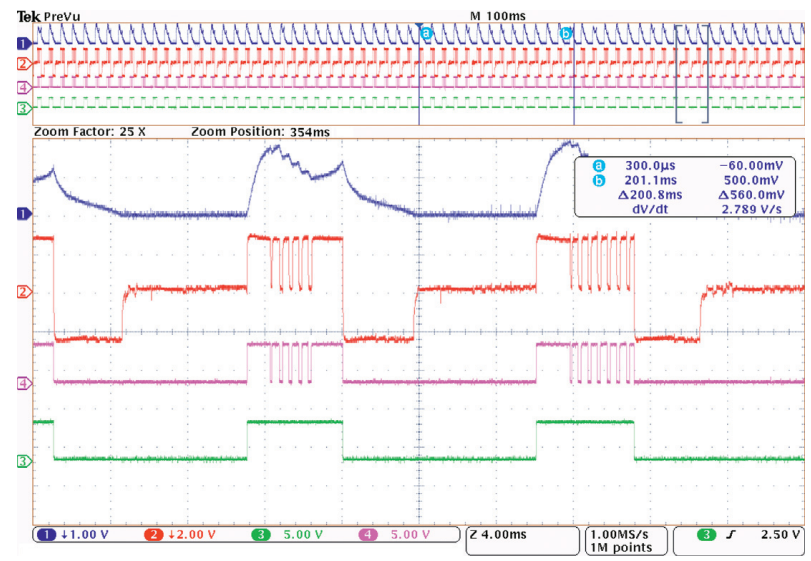

FIGURE 10: Voltage and switching state diagram of the MP-DITC system in stable operation.

$19 \mathrm{Nm}$, the torque is between $19.7 \mathrm{Nm}$ and $21.1 \mathrm{Nm}$, and the torque ripple is $1.4 \mathrm{Nm}$. In DITC hysteresis control system, the torque is between $23 \mathrm{Nm}$ and $24.9 \mathrm{Nm}$, and the torque ripple is $1.9 \mathrm{Nm}$; when the load is reduced as MP-DITC, the time required is $2 \mathrm{~s}$; when the load is $19 \mathrm{Nm}$, the torque is between $19.5 \mathrm{Nm}$ and $21.3 \mathrm{Nm}$, and the torque ripple is $1.8 \mathrm{Nm}$. The performance of MP-DITC strategy is superior to hysteresis DITC control strategy (Table 2).

Figure 10 shows the waveform of phase current, phase voltage, and switching state oscilloscope when the motor is running stably, line 1 (blue) is the current of phase $\mathrm{A}$, line 2 (red) is the voltage of phase A, and line 3 (purple) and line 4 (green) are the top and bottom switches of the drive circuit of phase.
The upper switch tubes are turned on in the PWM period, and because the torque error is greater than $T_{m}$, apply $+U_{\mathrm{DC}}$ to the winding, the torque increases rapidly, and the torque error decreases, but it is still greater than zero. At the end of the phase conduction, the winding discharges quickly and enters the next phase's conduction range. Figure 10 shows that the algorithm designed in system is used under different conditions, the PWM strategy complements the "blind zone" of the hysteresis strategy effectively, and the change of current is accompanied by the change of torque signal, which realizes high-performance torque control.

Figure 11 shows the part waveform of three-phase current in startup process, where line 1 (blue) is the current 
TABLE 2: Dynamic response comparison table.

\begin{tabular}{|c|c|c|c|}
\hline & Range of torque error before load shedding/torque ripple & Response time & $\begin{array}{l}\text { Range of torque error after load shedding/torque } \\
\text { ripple }\end{array}$ \\
\hline DITC & $23-24.9 \mathrm{Nm} / 1.9 \mathrm{Nm}$ & $2 \mathrm{~s}$ & $19.5-21.3 \mathrm{Nm} / 1.8 \mathrm{Nm}$ \\
\hline $\begin{array}{l}\text { MP- } \\
\text { DITC }\end{array}$ & $23.1-24.6 \mathrm{Nm} / 1.5 \mathrm{Nm}$ & $0.4 \mathrm{~s}$ & $19.7-21.1 \mathrm{Nm} / 1.4 \mathrm{Nm}$ \\
\hline
\end{tabular}

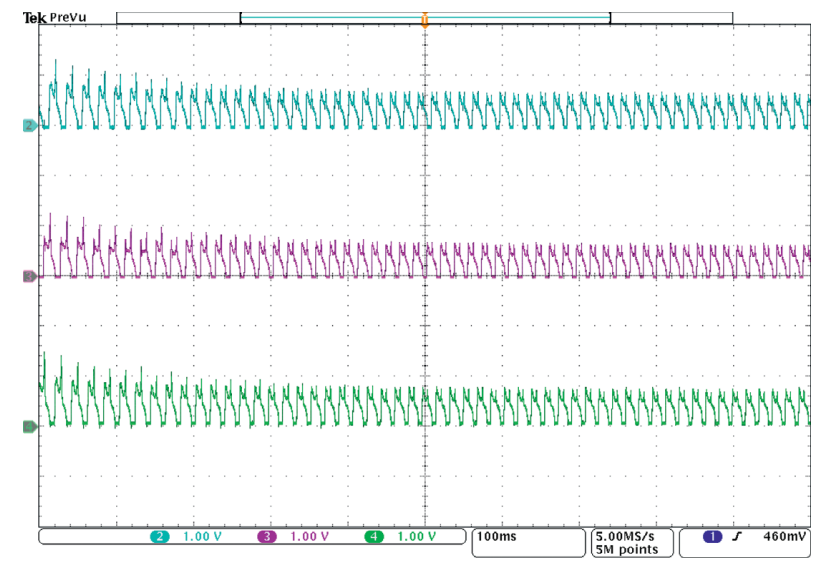

Figure 11: Current diagram of the MP-DITC system in startup process.

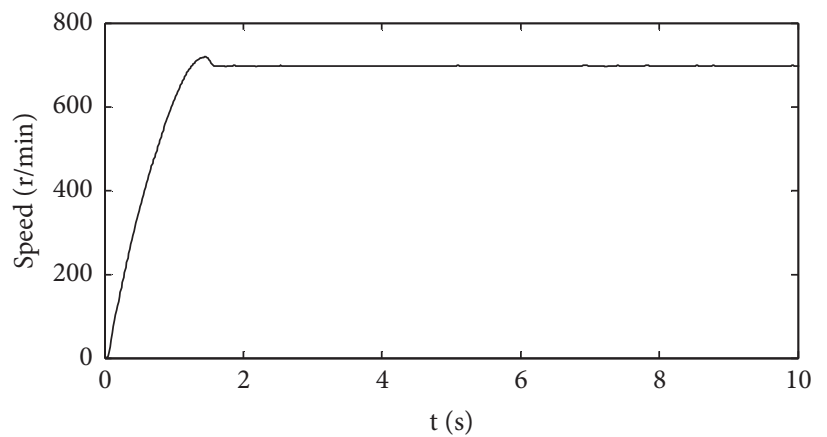

(a)

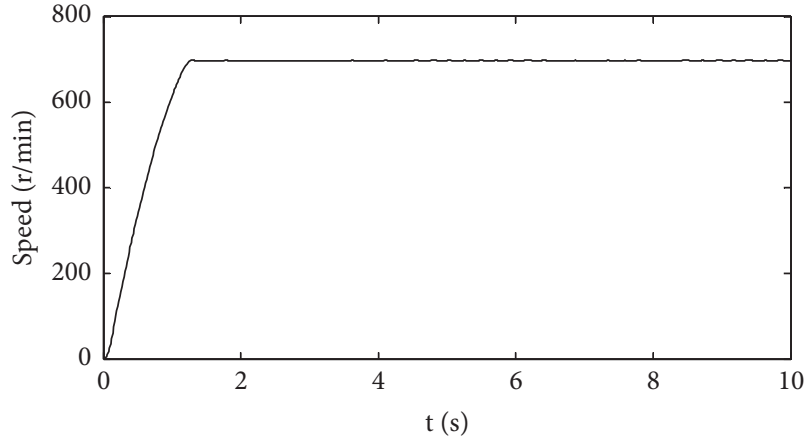

(b)

FIGURE 12: Speed diagram of the MP-DITC system. (a) Waveform of DITC speed. (b) Waveform of MP-DITC speed.

of phase $\mathrm{A}$, line 2 (red) is phase $\mathrm{B}$, and line 3 (purple) is phase C. All these waveforms reflect the dynamic booting process on current. As the speed approaches the target speed of $700 \mathrm{rpm}$ as in Figure 12(b) shown in MP-DITC, which is with load at $6 \mathrm{Nm}$, current will decay to stable state. Figures 12(a) and 12(b) show the speed waveform of SRM, where load is $6 \mathrm{Nm}$, which is acquired by LabVIEW and described by Matlab. Figure 12(a) shows that the speed of response time of steady state is $1.41 \mathrm{~s}$, and speed overshoot is about 20.2 r/min of DITC. Figure 12(a) shows that the speed of response time of steady state is $1.07 \mathrm{~s}$, and speed overshoot is about $4.3 \mathrm{r} / \mathrm{min}$ of MP-DITC. Figure 12 reflects that MPDITC has better performance in speed response than DITC.

\section{Conclusion}

Aiming at the large torque ripple of SRM, with analysis of SRM theory, a control method combining direct instantaneous torque hysteresis control and pulse width modulation is proposed. The traditional hysteresis DITC is compared and analyzed. The simulation model and experimental platform of motor control are built based on Matlab/ Simulink. For most of hysteresis DITC, error level is hard to set for hysteresis. Even if error level is rational, it may cause IGBT transistors to exceed the response frequency. If torque error is smaller than error level, hysteresis cannot respond to torque error. The real-time torque is collected by torque 
sensor, thinking of torque as a variable controlled directly. Executing different control strategies in different conduction regions, the generated control signal acts on the power converter directly. Comparing the simulation results with the experimental results, the algorithm combines hysteresis strategy and PWM strategy well. The system has fast response speed. It can avoid the defect of hysteresis control and reduce torque ripple effectively.

\section{Data Availability}

The raw/processed data used to support the results of this study have not been provided as they are also part of an ongoing study.

\section{Conflicts of Interest}

The author declares no conflicts of interest.

\section{Acknowledgments}

This research was funded by the Science and Technology Department Industrial Public Relations of Shaanxi Province, under Grant no. 2016GY064; Subsidy Fund of Key Laboratory of Shaanxi Province, under Grant no. 2014SSJ2002; and Special Project of Shaanxi Provincial Department of Education, under Grant no. 2013JK1002.

\section{References}

[1] R. Krishnan, Switched Reluctance Motor Drives: Modeling, Simulation, Analysis, Design and Applications, CRC Press, London, UK, 2001.

[2] M. Abd Elmutalab, A. Elrayyah, T. Husain, and Y. Sozer, "Extending the speed range of a switched reluctance motor using a fast demagnetizing technique," IEEE Transactions on Industry Applications, vol. 54, no. 4, pp. 3294-3304, 2018.

[3] T. André Dos Santos Barros, P. J. Dos Santos Neto, M. V. De Paula, A. B. Moreira, P. S. Nascimento Filho, and E. Ruppert Filho, "Automatic characterization system of switched reluctance machines and nonlinear modeling by interpolation using smoothing splines," IEEE Access, vol. 6, pp. 26011-26021, 2018.

[4] C. Gan, Y. Chen, R. Qu, Z. Yu, W. Kong, and Y. Hu, "An overview of fault-diagnosis and fault-tolerance techniques for switched reluctance machine systems," IEEE Access, vol. 7, pp. 174822-174838, 2019.

[5] F. Qi, A. Stippich, I. Ralev, A. Klein-Hessling, and R. W. De Doncker, "Model predictive control of a switched reluctance machine for guaranteed overload torque," IEEE Transactions on Industry Applications, vol. 55, no. 2, pp. 1321-1331, 2019.

[6] R. Shahbazi, S. M. Saghaiannezhad, and A. Rashidi, "A new converter based On DITC for improving Torque ripple and power factor in SRM drives," in Proceedings of the 2020 11th Power Electronics, Drive Systems, and Technologies Conference (PEDSTC), pp. 1-5, Tehran, Iran, 2020.

[7] B. Singh and A. Anand, "Power factor correction in modified SEPIC fed switched reluctance motor drives," in IEEE Transactions on Industry Applications, vol. 54, no. 5, pp. 4494-4505, 2018.
[8] Y. Tang, Y. He, F. Wang, D. Lee, J. Ahn, and R. Kennel, "BackEMF-based sensorless control system of hybrid SRM for highspeed operation," IET Electric Power Applications, vol. 12, no. 6, pp. 867-873, 2018.

[9] M. Asgar and E. Afjei, "Radial force reduction in a new flat type double-stator switched reluctance motor," IEEE Transactions on Energy Conversion, vol. 31, no. 1, pp. 141-149, 2015.

[10] C. Choi, S. Kim, Y. Kim, and K. Park, "A new torque control method of a switched reluctance motor using a torque-sharing function," IEEE Transactions on Magnetics, vol. 38, no. 5, pp. 3288-3290, 2002.

[11] H. Li, B. Bilgin, and A. Emadi, "An improved torque sharing function for torque ripple reduction in switched reluctance machines," IEEE Transactions on Power Electronics, vol. 34, no. 2, pp. 1635-1644, 2019.

[12] J. Ye, B. Bilgin, and A. Emadi, "An extended-speed low-ripple torque control of switched reluctance motor drives," IEEE Transactions on Power Electronics, vol. 30, no. 3, pp. 14571470, 2015.

[13] A. David Cheok and Y. Fukuda, "A new torque and flux control method for switched reluctance motor drives," IEEE Transactions on Power Electronics, vol. 17, no. 4, pp. 543-557, 2002.

[14] S. K. Sahoo, S. Dasgupta, S. K. Panda, and J.-X. Xu, “A Lyapunov function-based robust direct torque controller for a switched reluctance motor drive system," IEEE Transactions on Power Electronics, vol. 27, no. 2, pp. 555-564, 2012.

[15] K. Tomczewski and K. Wrobel, "Improved C-dump converter for switched reluctance motor drives," IET Power Electronics, vol. 7, no. 10, pp. $2628-2635,2014$.

[16] L. M. Pestana, M. R. A. Calado, and S. Mariano, "Direct instantaneous thrust control optimization of a linear switched reluctance actuator by pulse-width modulation duty ratio adjustment," in Proceedings of the IEEE 14th International Conference on Environment and Electrical Engineering, pp. 464-468, Roma, Italy, May 2014.

[17] J. Fan and Y. Lee, "A novel average torque control of switched reluctance motor based on flux-current locus control," $\mathrm{Ca}$ nadian Journal of Electrical and Computer Engineering, vol. 43, no. 4, pp. 273-281, 2020.

[18] X. Dang, Y. Shi, and H. Peng, "Torque-flux linkage recurrent neural network adaptive inversion control of torque for switched reluctance motor," IET Electric Power Applications, vol. 14, no. 9, pp. 1612-1623, 2020.

[19] T. Kusumi, T. Hara, K. Umetani, and E. Hiraki, "Phasecurrent waveform for switched reluctance motors to eliminate input-current ripple and torque ripple in low-power propulsion below magnetic saturation," IET Power Electronics, vol. 13, no. 15, pp. 3351-3359, 2020.

[20] Z. Shuguang, L. Mingtian, H. Shenglong, and W. Hao, "Torque ripple reduction of switched reluctance motor by optimising switch angle based on analytical modelling," IET Electric Power Applications, vol. 14, no. 8, pp. 1488-1495, 2020.

[21] Q. Sun, J. Wu, and C. Gan, "Optimized direct instantaneous torque control for SRMs with efficiency improvement," IEEE Transactions on Industrial Electronics, vol. 68, no. 3, pp. 2072-2082, 2021.

[22] S. Wang, Z. Hu, and X. Cui, "Research on novel direct instantaneous torque control strategy for switched reluctance motor," IEEE Access, vol. 8, pp. 66910-66916, 2020.

[23] A. Xu, C. Shang, J. Chen, J. Zhu, and L. Han, "A new control method based on DTC and MPC to reduce torque ripple in SRM," IEEE Access, vol. 7, pp. 68584-68593, 2019. 
[24] R. B. Inderka and R. W. A. A. De Doncker, "DITC-direct instantaneous torque control of switched reluctance drives," IEEE Transactions on Industry Applications, vol. 39, no. 4, pp. 1046-1051, 2003.

[25] R. B. Inderka and R. W. A. A. De Doncker, "High-dynamic direct average torque control for switched reluctance drives," IEEE Transactions on Industry Applications, vol. 39, no. 4, pp. 1040-1045, 2003.

[26] N. H. Fuengwarodsakul, M. Menne, and R. B. Inderka, "Highdynamic four-quadrant switched reluctance drive based on DITC," IEEE Transactions on Industry Applications, vol. 41, no. 5, pp. 1232-1242, 2005.

[27] H. Zeng, H. Chen, and J. Shi, "Direct instantaneous torque control with wide operating range for switched reluctance motors," in IET Electric Power Applications, vol. 9, no. 9, pp. 578-585, 2015.

[28] D. Liang and J.-A. Lee, "Direct instantaneous torque control of switched reluctance machines using 4-level converters," in IET Electric Power Applications, vol. 3, no. 4, pp. 313-323, 2009.

[29] S. Yao and W. Zhang, "A simple strategy for parameters identification of SRM direct instantaneous torque control," IEEE Transactions on Power Electronics, vol. 33, no. 4, pp. 3622-3630, 2018.

[30] L. Liu, M. Zhao, X. Yuan, and Y. Ruan, "Direct instantaneous torque control system for switched reluctance motor in electric vehicles," Journal of Engineering, vol. 2019, no. 16, pp. 1847-1852, 2019. 